\title{
Welfare State Development in Latin America and the Caribbean (1970s-2000s): Multidimensional Welfare Index, Its Methodology and Results
}

\author{
Gibrán Cruz-Martínez
}

Accepted: 16 December 2013/Published online: 1 January 2014

(C) Springer Science+Business Media Dordrecht 2013

\begin{abstract}
There is an ongoing debate between focalization and universalization on welfare policies as the best way to develop the welfare state in Latin America and the Caribbean. However, there is a need to develop a measure that exhibits the multidimensional nature of the welfare state, instead of focusing on the social spending dimension. Segura-Ubiergo (The political economy of the welfare state in Latin America: globalization, democracy and development. Cambridge University Press, New York, 2007) constructed a welfare effort index (WEI) to facilitate understand the relative degrees of welfare state development among Latin American countries. The WEI focuses mainly on social spending and ignores the other dimensions of welfare. Based on a comparative analysis of 17 Latin American countries and following the methodology of Segura-Ubiergo, a new index that aims at enriching the WEI was constructed. The new index is multidimensional in that it has eight indicators relating to three dimensions of welfare: social spending, coverage of welfare programs and outcome of welfare institutions. Principal component analysis was used for reducing the indicators into three indexes that represent three proposed dimensions of welfare. The combination of these three indexes gives the multidimensional welfare index. The results of the index account for more than $75 \%$ of the data variance.
\end{abstract}

Keywords Welfare state $\cdot$ Latin America $\cdot$ Social policy $\cdot$ Principal component analysis · Welfare effort

\section{Introduction}

During the last few decades, researchers' interest has been on the increase in studying and analyzing different aspects of Latin American welfare states. The study of Mesa-

G. Cruz-Martínez (更)

Universidad Complutense de Madrid, Madrid, Spain

e-mail: gcruzmartinez@cps.ucm.es 
Lago (1994) marks the beginning of studies on analysis of social security systems; Fernando Filgueira complemented Mesa-Lago's approach using other types of variables, such as the following: the degree of social services coverage; levels of public spending; degree of public benefits; and indicators showing the degree of social development. Molina (2006) examined the possibility of a reform and transformation of the Latin American welfare state, while Gough and Wood (2004) made a comparative analysis of the welfare state regimes of Latin American and other regions. Barba (2006), influenced by Esping-Andersen (1990, 1996), identified three ideal types of welfare regimes in the region; Martínez Franzoni and Voorend (2009) performed a typological construction of welfare regime scheme where empirical homogeneity is not required among countries in the same ideal welfare regime, instead, the countries need common and relevant patterns that describe the welfare as the means to assess capacity of collective risk management. Several researchers analyzed targeted welfare programs-known as conditional cash transfer programs (Barrientos 2011; Villatoro 2005; Rawlings and Rubio 2003; Sewall 2008). Huber et al. (2008) assessed the determinants of social spending in the region. These and many other aspects of the Latin American welfare state were examined in recent decades, although little attention was devoted to analyze the degree of welfare state development. The purpose of this paper is to contribute to the study of the welfare state development by proposing a new index that measures the relative development of the welfare state of Latin American and Caribbean countries, with a multidimensional perspective. The pioneering study of Segura-Ubiergo (2007) is the main source for assessing the level of welfare development in Latin America.

Segura-Ubiergo (2007) wonders how some Latin American countries could historically develop more extensive welfare states than did the other countries in the region? His research examines how, in Latin American countries, a combination of some economic and political factors contributed to the expansion of the welfare state to a greater extent than in others. Based on a comparative analysis and by constructing an index of welfare effort, the author identifies five countries ${ }^{1}$ in Latin America with a relatively more developed welfare state, in comparison to that of other countries in the region.

For the present analysis, to review and complement the results of Segura-Ubiergo (2007), three more countries (Colombia, Panamá and Puerto Rico) will be added to his list of fourteen. ${ }^{2}$ For constructing a multidimensional index that reflects the relative development of the welfare states in the region with a more comprehensive perspective, eight (8) indicators relating to three welfare dimensions will be considered.

\section{Welfare State Development in a Developing Region}

Welfare states from Latin American and the Caribbean are considered welfare states in transition (Esping-Andersen 1996; Huber 1996), emerging welfare states (Huber and Stephens 2012), or developmental welfare state in the making (Riesco 2009). Meaning that

\footnotetext{
1 Argentina, Brazil, Chile, Costa Rica and Uruguay.

${ }^{2}$ Hopefully, in the near future Cuba, Honduras, Nicaragua, Guiana, Belize, Haiti, Jamaica and other Caribbean islands may also be added to the analysis in order to have a complete study of the welfare states of Latin America and the Caribbean.
} 
their welfare institutions and programs aren't yet developed as their counterparts in Europe and other industrialized countries. In this article an index to measure the welfare state development is proposed. This index pretend to reflects the level of development among the emerging/developmental welfare state in the region. The term welfare state development refers to progress and institutionalization of welfare programs that address social risks of the population in order to assure a common well-being. Following EspingAndersen (1990) it could be argued that the development of the welfare state refers to the process of institutionalization of welfare programs, to ensure a basic minimum of entitled social protection to the population.

Before analyzing the results of Segura-Ubiergo, presented in Table 1, it would be important to present certain details that will enrich the analysis. The period used by the author for study is the welfare state expansion and consolidation era in Latin America. "A study of the origins of the welfare state, both in advanced capitalist democracies and in Latin America, would require a careful analysis of the political and economic factors that led to the passage of the first social security and welfare laws in the second and third decades of the century (earlier for some countries). By contrast, an analysis of the development of the welfare state would focus on the socioeconomic and political factors that transformed initial social legislation into increasingly greater welfare entitlements, public health systems and public education systems". The welfare state development and consolidation period in Latin American (from 1940s to the present) could be divided into two periods according to Segura-Ubiergo (2007): the pre-globalization period that covers the period roughly from 1945 to 1979 , and the globalization period that covers the period from 1979 to the present. The splitting of the development of Latin America's welfare state into two periods was necessitated by the major policy transition of the 1980s (beginning of globalization period), when the largest countries in the region started to gradually leave behind Industrialization by Substitution of Imports (ISI) policies and started opening up to the capital's international market.

Segura-Ubiergo (2007) analysis (see Table 1) shows a clear division of Latin American countries into two groups, based on the role and scope of state responsibility towards social security. The first group consists of countries with a high welfare effort and the second group with a relatively low welfare effort. The author uses principal component analysis (PCA) and reduces the four welfare indicators into one index. Segura-Ubiergo's welfare index accounts for about $91 \%$ of the variation in the four components or indicators analyzed, and hence it could be considered a good summaryindicator of the four subcomponents of welfare effort. However, the author (2007, p. 25) comments that three of the four components of his welfare index are social spending measures. Because of the over-riding importance given to social expenditure, his index is subject to criticism.

To improve Segura-Ubiergo's welfare index, four new indicators were added to the four already present in his analysis. Following are the new indicators: (a) percentage of employees with retirement coverage, (b) number of hospital beds per ten thousand inhabitants, (c) percentage of population with high level of education, and, (d) the improbability of suffering infant mortality (under 5 years of age). This index was constructed for the period known as the globalization era (1973-2010) and what Sottoli (2000) calls the new social policy era (with the liberalization of economy and focalization of social policy) that left behind the traditional, interventionist and universal (in theory) social policy. 


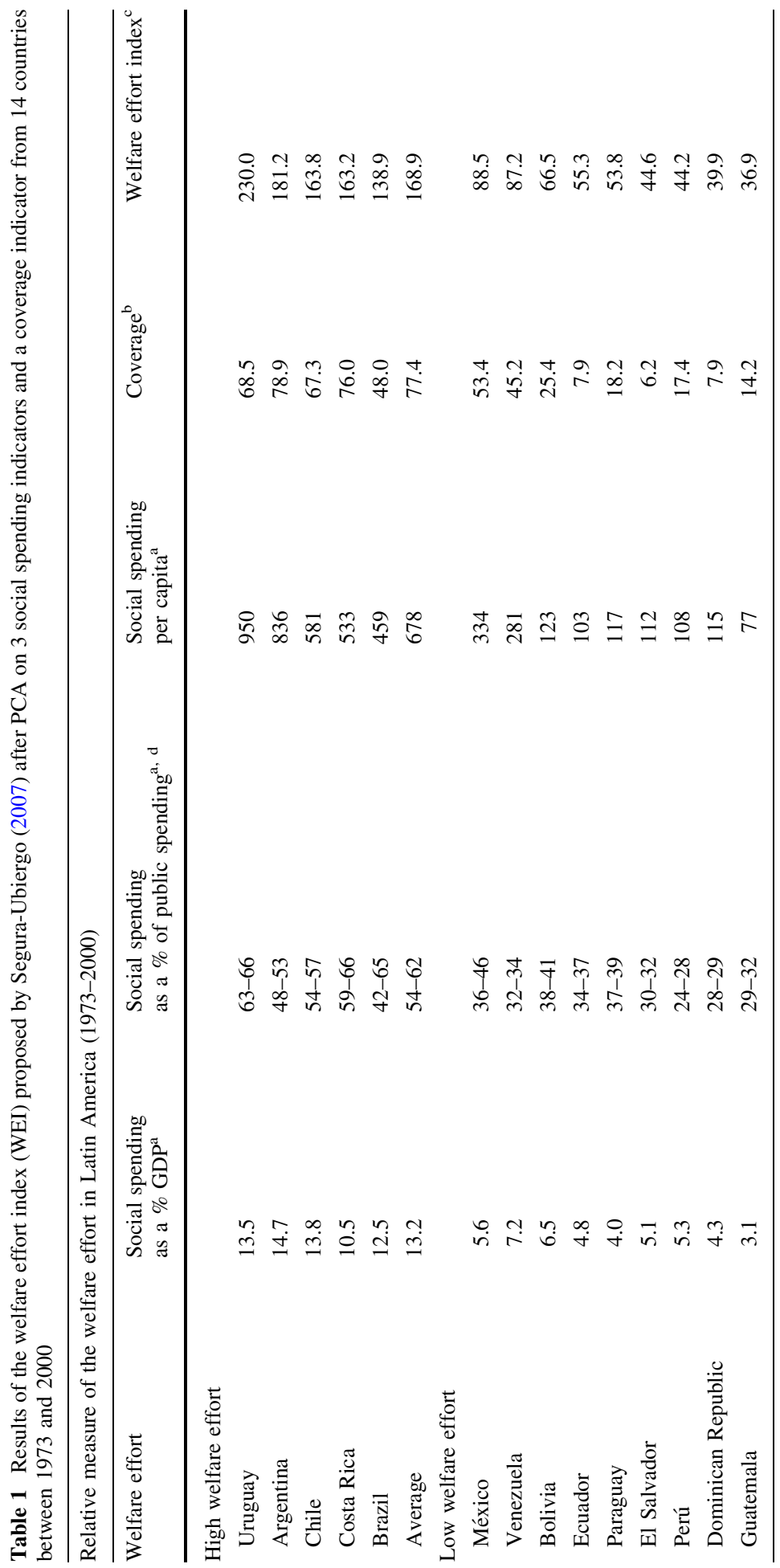




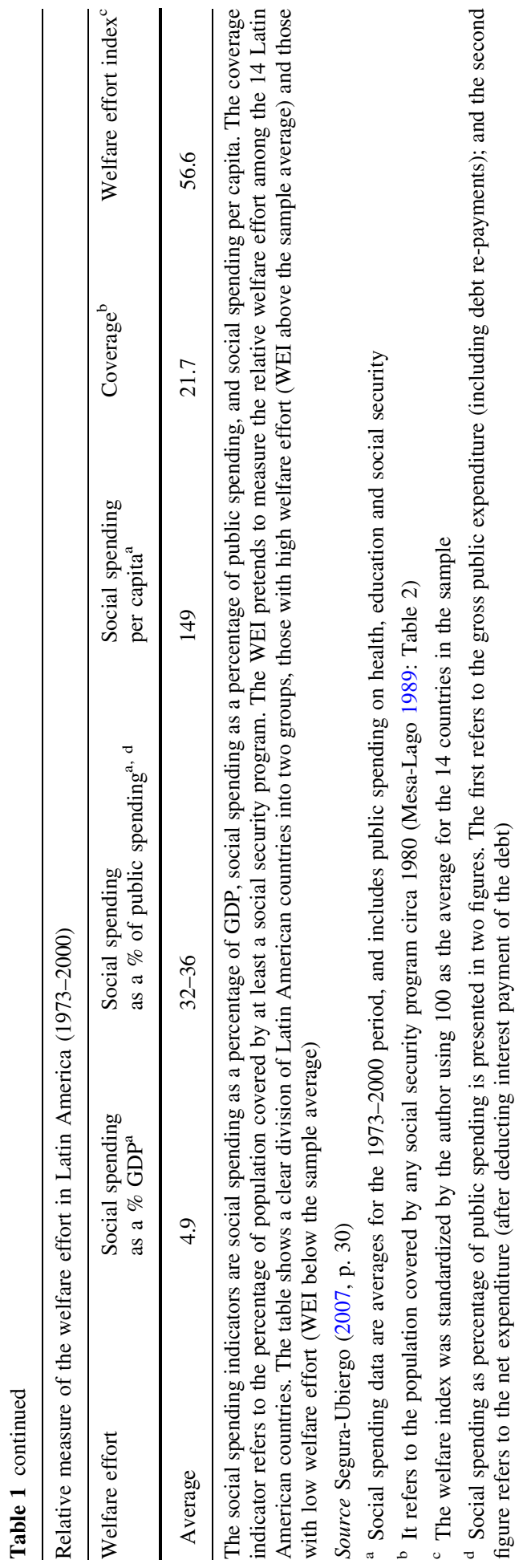




\section{Components of the New Welfare Index}

To take into account different dimensions of welfare, eight indicators, representing three welfare dimensions, were included in the new welfare index for analysis. Social spending as a percentage of gross domestic product (GDP), social spending as a percentage of public spending and social spending per capita are the three indicators that represent the spending dimension in the new welfare index. Percentage of population covered by at least a social security program, percentage of employees with retirement coverage, and hospital beds per ten thousand inhabitants are the three indicators that represent the extent of welfare programs coverage in the new index. Finally, percentage of population with high level of education, and the improbability of suffering infant mortality (under 5 years of age) are the indicators that represent the outcome dimension in the new index. Data for the 8 indicators used in this article are provided in the "Appendix".

First, each of the three welfare dimensions will be reduced to individual indexes of welfare. Then, each individual index will have the same weight in the construction of the multidimensional welfare index. Before introducing the methodology and index construction, a more detailed explanation of the eight (8) indicators is presented below.

\subsection{Spending Dimension}

Three of the four components used by Segura-Ubiergo in his welfare index are included in the spending dimension of the new multidimensional welfare index proposed here. The first of these indicators is social spending as a percentage of the GDP. The value of this indicator represents the importance of social spending as compared to the total monetary value of the production of final goods and services in each country. Because there is no generalized measure of social spending in the database that includes the countries analyzed in this study, it is important to mention that social spending, as used in this study, relates to spending on health, education and social security programs. In the case of Puerto Rico, Colombia and Panama, the details of spending had to be calculated and the data required came from the following sources: Alameda-Lozada and Diaz-Rodriguez (2009); CEPAL (1980, 1990, 1991, 2000, 2002, 2004); Junta de Planificacion (1984a, b, 1990, 2000, 2008); Mitchell (2003); data for the remaining countries came from Segura-Ubiergo's study $(2007,29)$.

The second indicator is social spending in terms of percentage of public spending. The value of public spending represents the net value after deducting the payment of debt interest. In the case of Puerto Rico, Colombia and Panama, these details had to be calculated, and the data required came from the following sources: CEPAL (1980, 1990, 1991, 2000, 2002, 2004); Junta de Planificacion (1984a, b, 1990, 2000, 2008); data for the remaining countries came from Segura-Ubiergo's study (2007, 30). This value helps determining the priority that each State gives, through its government, for education, health and social security.

The third indicator in this dimension is social spending per capita. Just as the first two indicators, this is also an average of the values of the period 1973-2000. In the case of Puerto Rico, Colombia and Panama, the values had to be calculated, and the data came from Barriento (2012); CEPAL (1980, 1990, 1991, 2000, 2002, 2004); Junta de Planificacion (1984a, b, 1990, 2000, 2008); data for the remaining countries came from SeguraUbiergo's study $(2007,30)$. This indicator is important for comparative studies of social expenditure as a resource received by citizens in transfers from the state. These three indicators will be reduced, through principal component analysis, to a social spending dimension index (SSDI). 


\subsection{Coverage Dimension}

The coverage dimension also consists of three (3) indicators. The first is the percentage of population covered by social security around 1980 . This is the fourth and last component used in Segura-Ubiergos's welfare index. Data for all countries included in this analysis, with the exception of Puerto Rico, came from Table 2 in Mesa-Lago (1989); the values for Puerto Rico had to be calculated from the data available in Colón Reyes (2011). ${ }^{3}$ This indicator gives the population percentage covered by any social security program in the respective country.

The second coverage indicator is the percentage of employees with retirement coverage (\% ERC). This refers to the average number of active employees entitled to receive pension during the first decade of the century (2000-2010). The data for this was taken from the Socioeconomic Database for Latin America and the Caribbean (SEDLAC), except for Panama and Puerto Rico. The data for calculating \% ERC of Puerto Rico came from the Bureau of Labor Statistics (Negociado de Estadisticas del Trabajo 2011, p. Table 19), ${ }^{4}$ and that for Panama from the National Institute of Statistics and Census (Instituto Nacional de Estadistica y Censo (INEC) 2004-2005, 2005-2006, 2006-2007, 2007-2008, 2008-2009). ${ }^{5}$

The third coverage indicator is the number of hospital beds for every ten thousand inhabitants. ${ }^{6}$ The data for this came from the Socioeconomic Database for Latin America and the Caribbean (SEDLAC), except for Puerto Rico which was taken from the Pan American Health Organization (2012). The indicator represents the level of health sector coverage in the welfare state. One might ask here "Why use this indicator instead of other indicators of health coverage?". Any person who specializes in comparative analysis knows that finding data and relevant variables for all the countries is almost impossible, and particularly so in Latin America. Only two indicators, which reflect health coverage, are available for the 17 cases of this study: the population per physician and hospital beds per capita. To choose between these two indicators, one must identify the indicator that demonstrates a more direct coverage of the welfare institutions in the respective country. This explains why the number of hospital beds per ten thousand inhabitants was selected as the health coverage indicator, and not doctors per capita.

\footnotetext{
${ }^{3}$ To obtain the percentage of population covered by a social security program in Puerto Rico, the following formula was applied: $P C C S=\frac{\sum(S S B+E L F+P P A N O R)}{\text { Population }}$. The population covered by the social security (PCSS) would be obtained by dividing the sum of three components over the magnitude of the entire population. Following are the three components on the numerator: (a) social security beneficiaries (SSB), (b) the employed labour force (in the formal sector) (ELF) and, (c) the population that receives PAN funds as their only revenue (PPANOR). PAN is the focalized food program in Puerto Rico for people below the poverty line; it is also known as food stamps.

4 To obtain the percentage of employees with retirement coverage (\% ERC), the following formula was applied: $\% E R C=\frac{E L F}{(E L F+I L F)}$. In Puerto Rico, the employed labour force (in the formal sector) pay their taxes (via monthly deductions) and therefore are included as an employed person entitled to old-age social security benefits, which can be viewed as a retirement benefit. \% ERC value was obtained by dividing the employed labour force (in the formal sector) by the number of workers in both formal and informal sectors. The informal sector workers value was calculated using the "Informal Labor Force" (ILF) from Pol and Silvestrini (2004, p. 115).

5 The percentage of employees with retirement coverage in Panamá was obtained by dividing the data of active contributors insured, among the total employed population.

${ }^{6}$ It was determined to use, as denominator, population figures presented in thousands, because of its utility for this research.
} 
These three indicators will be reduced through PCA to a coverage dimension index (CDI).

\subsection{Outcomes Dimension of the Welfare Institutions}

Finally, for this dimension of welfare, two indicators were considered. The first one is the percentage of the population with at least 1 year of "higher" (post-secondary) education. This indicator shows the proportion of adults, in the age group of 25-65 years, with more than 13 years of formal education. ${ }^{7}$ The data for all the countries, except Puerto Rico, came from the Socioeconomic Database for Latin America and the Caribbean (SEDLAC), and that for Puerto Rico from the Puerto Rico Planning Board Junta de Planificacion (2000a) and US Census Bureau (n.d.). The data is the average of the results of this indicator during the first decade of the century (2000-2010). This indicator not only reflects the success of educational institutions in retaining their students to complete primary and secondary education, but also indicates indirectly which countries have been successful in this regard by creating various programs and institutions.

The second outcome indicator is the improbability of children under 5 years suffering infant mortality. Data for this came from the information and analysis of the health project of Pan American Health Organization (PAHO) (Pan American Health Organization 2012). The data refers to the average of the indicators in the first decade of the century (2000-2010). The source data had to be converted into negative form (improbability of suffering infant mortality), so that when performing the principal component analysis, the statistical program recognizes the higher value cases as the most desirable ones, and not vice versa. So, the country with the lowest infant mortality rate, has the highest score in this indicator, because it reflects the improbability of suffering infant mortality. In other words, infant mortality should be lower in countries with more developed welfare health institutions. This indicator thus reflects the success of healthcare institutions.

This raises the question, "Why not one uses the life expectancy at birth to measure the performance of health institutions?" While life expectancy at birth is one of the most used statistics to measure quality of life and human development, it was not considered suitable for this study, because there are many factors that affect life expectancy at birth that are unrelated to the level of welfare state development. Life expectancy at birth is "the years that a newborn can expect to live if an age-specific mortality pattern prevailing at the time of his birth remains throughout his life" (PNUD 2011). This indicator is not intended to measure the life expectancy of a person at birth, but the probability of her or his survival beyond 5 years, because this is a more direct measure of the development of health institutions and thus the success of welfare institutions.

These two indicators will be reduced, through principal component analysis, to the outcomes dimension index (ODI).

\footnotetext{
7 The other components of the educational structure of Latin American and Caribbean countries, namely low degree of formal education (0-8 years) and medium level of education (9-12 years), can be observed in the SEDLAC database.
} 


\section{Methodology}

How does one calculate this new multidimensional welfare index? Before answering this question, it would be helpful to elaborate on how to use the PCA for calculating the new index.

\subsection{Principal Component Analysis (PCA)}

Principal component analysis (PCA) is a mathematical method developed by Pearson (1901) from a geometric perspective, which was subsequently revised algebraically by Hotelling (1933). It is now one of the most commonly used methods to reduce multidimensionality of a dataset (Schuschny and Soto 2009, p. 42). The goal of PCA is to explain most of the total variability observed in a set of variables with the fewest possible components (Uriel Jiménez 1995).

Wuensch (2004) notes that the intention of PCA is to extract a set of $\mathbf{p}$ variables to a set of $\mathbf{m}$ components representing the largest possible variance in the $\mathbf{p}$ variables. It could also be seen as the process of reducing a set of $\mathbf{p}$ variables to a set of $\mathbf{m}$ underlying dimensions of higher order.

These underlying components were inferred from the correlations between the $\mathbf{p}$ variables. Each component was estimated as a weighted sum of the $\mathbf{p}$ variables. The ith component is then given by the following:

$$
P C_{i}=W_{i 1} X_{1}+W_{i 2} X_{2}+W_{i p} X_{p}
$$

To reduce the original variables to the fewest possible components, it will be necessary that they correlate highly with each other; the higher the correlation with the original variables, the fewer the number of resulting components when performing the PCA. To measure the inter-correlation between the original variables, it is necessary to observe the correlation matrix, as well as the determinant test of the correlation matrix. The outcome of the test may determine the degree of correlation between the variables of original data and whether it is advisable to continue with the PCA. If the test results show that the determinant is very low, then it means that inter-correlation among the variables is very high; this in turn suggests that it is feasible to continue with the factor analysis. However, the determinant must not be zero, because in such a case the data would not be valid (OECD and European Commission 2008).

In addition, a series of calculations will be required before performing the PCA to check the statistical relevance of PCA to the data. To measure statistical relevance, the Bartlett test of sphericity was used. This test was used to test the null hypothesis that the variables were not correlated amongst themselves. That is, it was a check to determine if the correlation matrix was an identity matrix. According to the OECD and European Commission report, if the test results show a high value, whose reliability ( $p$ value) is $<0.05$, then the results can be considered valid In this case, the null hypothesis was rejected and the analysis continued (OECD and European Commission 2008, p. 67).

In a previous section of this paper, it was mentioned that the new multidimensional welfare index would assign the same weight to each of the three welfare dimensions. Each dimension will be a set of indicators, reduced by PCA. No doubt, the PCA could have been applied directly to the eight indicators to obtain the new index. In fact, that was the idea at the beginning of this study, but because such procedure does not satisfy the statistical rule of "sufficient number of cases for variables", it became necessary to adopt another approach to reduce the indicators to a multidimensional index. The new approach used the 
Human Development Index (HDI) methodology as the reference. The HDI includes three indexes (Life Expectancy Index, Education Index and Income Index), which are reduced to one composite indicator. The same procedure was followed here ${ }^{8}$ t the three welfare dimension indexes [Social Spending Dimension Index (SSDI), Coverage Dimension Index (CDI) and Outcomes Dimension Index (ODI)] were proposed to be combined into one composite indicator. That way, each of the three welfare dimensions will have the same weight in the Multidimensional Welfare Index (MWI). The following is the formula to obtain the MWI:

$$
M W I=\frac{\sum(S S D I+C D I+O D I)}{3}
$$

\subsection{Principal Component Analysis (PCA) Critics}

One of the disadvantages of PCA, as a method to reduce variables, is its high sensitivity to incorporation and presence of outliers. Further, the method tends to minimize the contribution of variables that have a different evolution or path from that of other indicators. This technique seeks homogeneity, rather than plurality of behaviors, and can be applied only when significant correlations exist (Schuschny and Soto 2009, pp. 58-59). Another important point to note is that, if the variables to be analyzed have a low standard deviation, they will have a low weight or load in the PCA (Vyas and Kumaranayake 2006, p. 461). Data that is presented category-wise (such as religion, ethnicity, gender, etc.) is not suitable for PCA, because the categories have to be converted into a quantitative scale that will not yield any coherent result. To overcome this problem, qualitative categorical variables should be recoded as binary variables (Vyas and Kumaranayake 2006, p. 463). All this debate about the use of PCA reflects that the main components are indices constructed artificially; PCA critics argue that this technique is arbitrary, because the method of choosing the number of components, and of the variables to be analyzed, is not well defined (Vyas and Kumaranayake 2006, p. 467).

The success of PCA in the reduction of variables depends on its ability to sum up a substantial proportion of the variance in the data with the least amount of components (indexes) and, if the components are more than one, it should be able to interpret each component meaningfully. It is also important to assess the effectiveness of PCA, where it can explain only a small proportion of the variance in the data analyzed by the first principal component. Paying attention to the variables included in the PCA is also important, especially in terms of checking their appropriateness to the objectives of the analysis (Abeyasekera 2002, p. 18). In spite of the disadvantages pointed out by some authors, PCA was considered an appropriate tool for this study in reducing the number of indicators.

\section{Multidimensional Welfare Index (MWI) Results: R}

To calculate the Multidimensional Welfare Index (MWI), various mathematical calculations had to be performed and "R" was used to compute them. As mentioned in the methodology section, before performing the PCA in each of the three individual indexes, the correlation between indicators was to be tested through a correlation matrix with data from the 17 cases (countries); the higher the correlation, the fewer would be the number of

\footnotetext{
${ }^{8}$ An arithmetic mean was used to reduce the 3 indexes (SSDI, CDI and ODI) to the composite MWI. Because the SSDI, CDI and ODI have the same range (0-1) there was no need to use the geometric mean as in the new HDI method.
} 
resulting components when performing the PCA. It will be ideal if there is only one resulting component after the PCA; that way, one index will represent each dimension.

\subsection{Data Correlation}

Looking at the correlation matrix, a positive correlation can be inferred between the indicators of each dimension. Variables of each dimension presented correlations above 0.50 in the correlation matrix, which confirm that when performing the PCA, the first principal component of each dimension should be able to summarize the information and may serve as individual dimensional index. Because correlation matrix, and not covariance matrix, was used in the PCA, individual indicators were given equal weight in forming the major components (Dunteman 1989, pp. 22-23).

Once the level of correlation among the indicators was checked and found to be high, two tests were necessary on each data set to assess the statistical relevance of the PCA and to confirm that the correlation between variables was high. The first test was the determinant of the correlation matrix. The determinant was calculated in $\mathrm{R}$, and the result is as follows:

$\begin{array}{ccc}>\operatorname{det}(\operatorname{cor}(S S D I)) & >\operatorname{det}(\operatorname{cor}(C D I)) & >\operatorname{det}(\operatorname{cor}(O D I)) \\ {[1] 0.0791064} & {[1] 0.2163995} & \text { [1] } 0.7473191\end{array}$

Even though the determinants of each correlation matrix were not as low as the determinant of the correlation matrix obtained from using the eight (8) welfare indicators (9.079839e-05), continuing with the PCA was found to be feasible.

The second test was Bartlett's sphericity. The test was calculated in $\mathrm{R}$ and the results, for each index, are as follows:

$>$ bartlett.test(SSDI)

Bartlett test of homogeneity of variances

data: SSDI

Bartlett's K-squared $=177.7924, \mathrm{df}=2, \mathrm{p}$-value $<2.2 \mathrm{e}-16$

$>$ bartlett.test(CDI)

Bartlett test of homogeneity of variances

data: CDI

Bartlett's K-squared $=15.3828, \mathrm{df}=2, \mathrm{p}$-value $=0.0004567$

$>$ bartlett.test(ODI)

Bartlett test of homogeneity of variances

data: ODI

Bartlett's K-squared $=31.5613, \mathrm{df}=1, \mathrm{p}$-value $=1.932 \mathrm{e}-0$

The Bartlett's test of sphericity confirmed the statistical relevance of the PCA, because the value of the test could be considered relatively high in each index and the reliability or $p$ value of each of the three individual indexes is also much lower than 0.05 , the critical value. 


\subsection{Principal Component Analysis (PCA) ${ }^{9}$}

For PCA, the function pca(x, cor = TRUE) under the library (labdsv) was used on R. This function uses prcomp (x), but includes different conventions for graphing and analyzing that will be used throughout this paper (Roberts n.d.).

David Roberts, author of the pca(x) function, notes that this function allows the researcher to specify the number of parameters on the calculation of the PCA. It has to be decided in advance whether to use correlation matrix or covariance. PCA is sensitive to the scale on which measured data is used in the analysis. Roberts recommends using PCA for a correlation matrix, because by doing so, all variables are treated equally (standardized mean $=0$ and $\mathrm{SD}=1$ ). Although all variables are measured on the same scale, Roberts recommends using the same correlation matrix to prevent the key variables from determining the outcome. In R, this means specifying cor = TRUE when writing the function $\mathrm{pca}(\mathrm{x})$. In addition, this function will generate an eigenvector for each column (variable) and a score for each row (Roberts n.d.). ${ }^{10}$

The results of PCA are on the expected lines; each index finished with as many components as the indicators used in the PCA. The aim of this analysis was to reduce the dimensions of welfare to the fewest possible indexes, losing minimum possible variance from the indicators used. But, how many principal components need to be retained without losing much information?

\subsection{Interruption Rules for Retaining Principal Components}

There are several general guidelines or rules for interruption in PCA. They are used to know when to stop the inclusion of retaining components in the analysis. Kaiser Criterion, scree plot and comprehensibility are the three rules most employed by methodologists, and they were applied to each index data.

Kaiser Criterion: To obtain the results of the eigenvalues, it was necessary to use the function eigen(cor[x]) in $\mathrm{R}$ and the results are as follows:

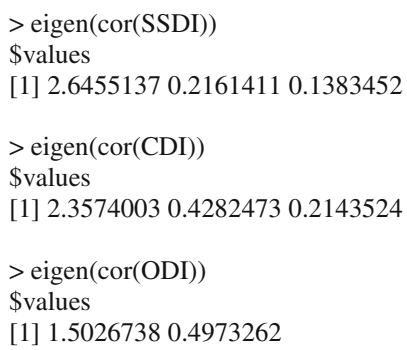

Kaiser criterion states that all factors or components, each with an eigenvalue below 1.0, be left out of the analysis. If this criterion is fulfilled, then it will be confirmed that only the first component, in each of the three (3) data sets, will be necessary for each index construction.

\footnotetext{
${ }^{9}$ Efforts are being made to increase the number of cases and to find other possibilities to overcome the problem of "too many variables, too few cases".

10 To obtain more information about this formula, please visit the site: www.ecology.msu.montana.edu/ labdsv/R/labs/lab7/lab7.html.
} 
Scree plot:

Catell (1965) proposed to continue the analysis with the components that presented eigenvalues prior to the sharp drop in the graph. By applying this rule to Figs. 1, 2 and 3, it can be reconfirmed that only the first principal component would be retained.

Comprehensibility:

Comprehensibility is the final criterion to be used for retention of key components. There is a consensus that the components be limited to as many as those whose meaning can be understood. According to this research, retaining only the first principal component is considered understandable, because the idea is to construct three welfare indexes, which will be combined to build the MWI. The high proportion of variance that is accounted for by the first principal component supports this comprehensibility. The first component alone accounts for over $75 \%$ of the data variance; more specifically $88.18 \%$ for the SSDI, $78.58 \%$ for the CDI and 75.13 for the ODI.

\subsection{Principal Component PC Scores and Individual Welfare Index}

To decide on the number of principal components to be retained in the PCA, the results of the three tests carried out, or the criteria used, were analyzed and it was decided to retain only the first principal component for each of the three individual indexes. Using the pc scores from the first principal component, the three individual welfare indexes (SSDI, CDI and ODI) were constructed.

In Tables 2, 3 and 4, the second column shows the pc score for each country, and the third column the individual welfare index after standardization of the data through a rescaling method. The indexes were standardized to make the data more comprehensible

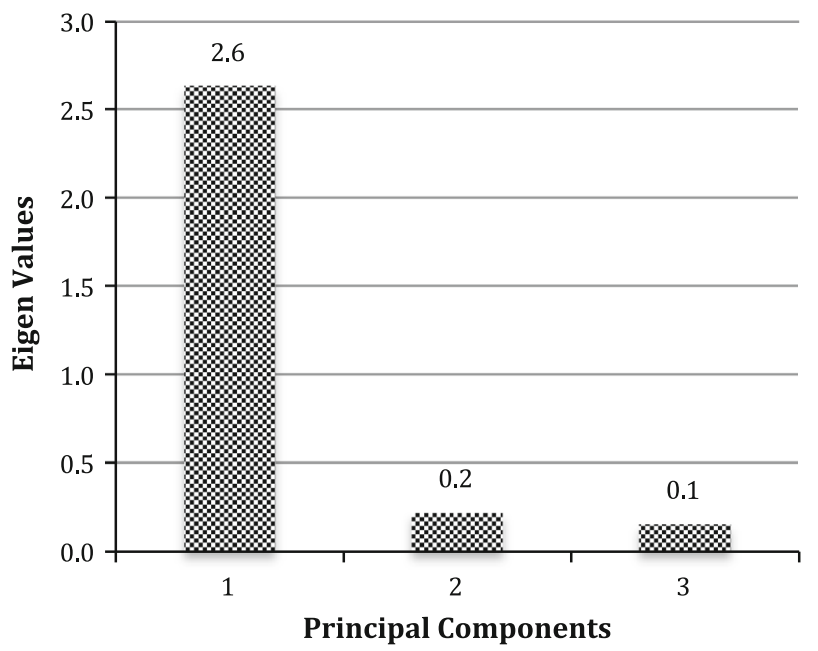

Fig. 1 Scree plot of SSDI principal components and their respective eigen values after PCA on 3 social spending indicators from 17 countries between 1970s and 2000s. Countries: Argentina, Bolivia, Brazil, Chile, Colombia, Costa Rica, Dominican Republic, Ecuador, El Salvador, Guatemala, México, Panamá, Paraguay, Perú, Puerto Rico, Uruguay and Venezuela. SSDI indicators: social spending as a percentage of GDP, social spending as a percentage of public spending and social spending per capita. SSDI is a composite indicator formed by three spending indicators reduced through PCA and used to rank countries on the social spending dimension of the Multidimensional Welfare Index 


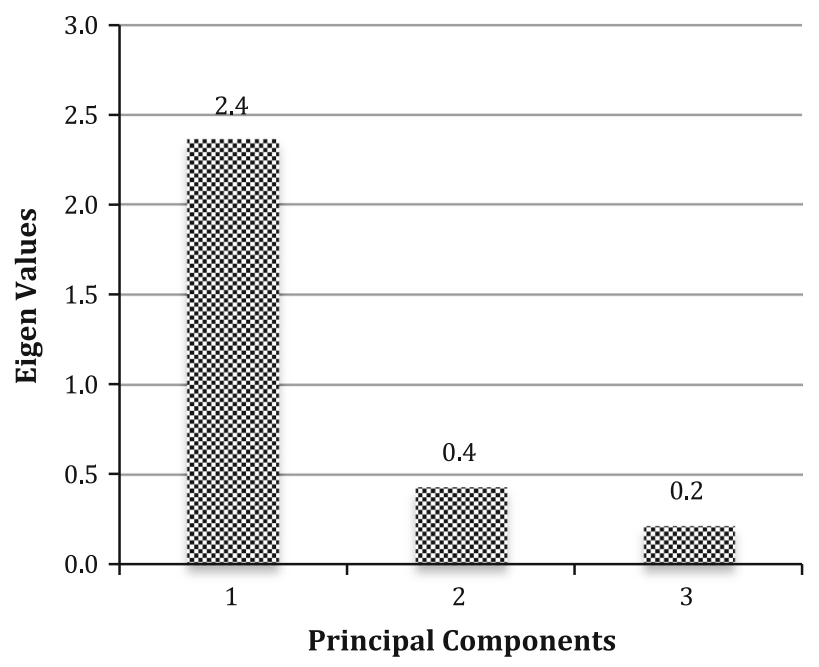

Fig. 2 Scree plot of CDI principal components and their respective eigen values after PCA on 3 coverage of welfare programs indicators from 17 countries between 1980s and 2000s. Countries: Argentina, Bolivia, Brazil, Chile, Colombia, Costa Rica, Dominican Republic, Ecuador, El Salvador, Guatemala, México, Panamá, Paraguay, Perú, Puerto Rico, Uruguay and Venezuela. CDI indicators: percentage of population covered by at least a social security program, percentage of employees with retirement coverage and hospital beds per ten thousand inhabitants. CDI is a composite indicator formed by three coverage of welfare programs indicators reduced through PCA and used to rank countries on the coverage dimension of the Multidimensional Welfare Index

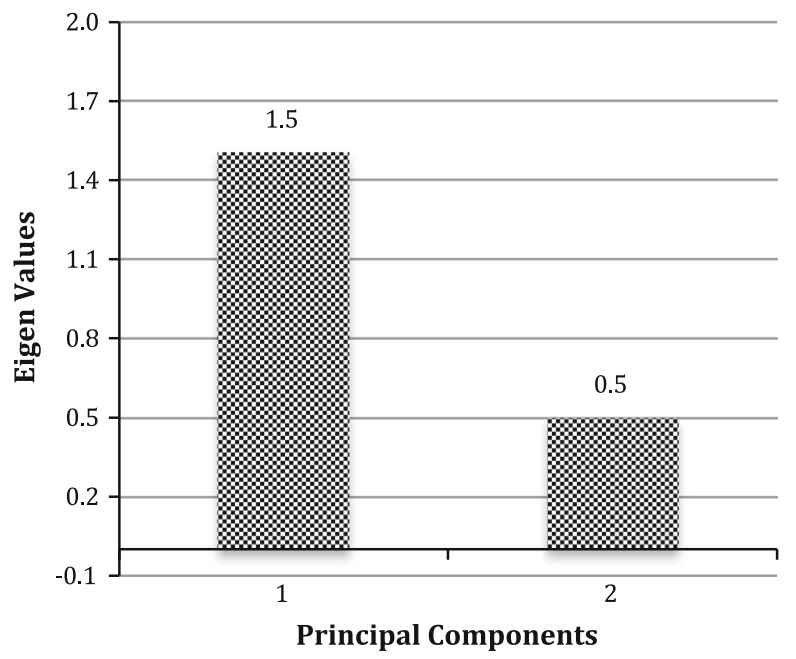

Fig. 3 Scree plot of ODI principal components and their respective eigen values after PCA on 3 outcomes of welfare institutions indicators from 17 countries between 2000 and 2010. Countries: Argentina, Bolivia, Brazil, Chile, Colombia, Costa Rica, Dominican Republic, Ecuador, El Salvador, Guatemala, México, Panamá, Paraguay, Perú, Puerto Rico, Uruguay and Venezuela. ODI indicators: percentage of population with high level of education, and the improbability of suffering infant mortality (under 5 years of age). ODI is a composite indicator formed by two outcomes of welfare institutions indicators reduced through PCA and used to rank countries on the outcomes dimension of the Multidimensional Welfare Index 
Table 2 Results of the social spending dimension index (SSDI) after PCA on 3 social spending indicators from 17 countries between 1973 and 2000

The SSDI results were standardized for comprehensibility (1.0 represents the country with the most developed social spending dimension, and 0.0 the least developed)

\begin{tabular}{lcl}
\hline & SSDI & $\begin{array}{l}\text { SSDI }(\max = \\
1 \mathrm{~min}=0)\end{array}$ \\
\hline Uruguay & -2.747 & 1.000 \\
Puerto Rico & -2.400 & 0.925 \\
Argentina & -2.136 & 0.867 \\
Chile & -1.681 & 0.768 \\
Brazil & -1.601 & 0.750 \\
Costa Rica & -1.514 & 0.731 \\
Colombia & 0.121 & 0.375 \\
México & 0.399 & 0.314 \\
Panamá & 0.460 & 0.301 \\
Venezuela & 0.792 & 0.229 \\
Bolivia & 0.902 & 0.205 \\
Paraguay & 1.342 & 0.109 \\
Ecuador & 1.345 & 0.108 \\
El Salvador & 1.498 & 0.075 \\
Perú & 1.648 & 0.042 \\
Dominican Republic & 1.729 & 0.025 \\
Guatemala & 1.842 & 0.000 \\
\hline & &
\end{tabular}

(1.0 represents the country with the most developed welfare dimension, and 0.0 the least developed).

\section{Multidimensional Welfare Index (MWI) Analysis}

After combining the three individual welfare indexes using the formula proposed in the methodology section, the MWI was constructed (See Table 5). Several conclusions can be deduced from the data of this Table, depending on the type of analysis made. In the following section, the rationale behind dividing the countries into three groups is briefly explained, followed by a brief analysis of the three groups, according to their MWI values and sample average values.

\subsection{Division of Countries into Three Groups According to Their Degree of Welfare Development}

After analyzing the data in Table 5, the first thing that attracts the reader's attention is the division of the 17 Latin American countries into three groups. The first group, comprising Puerto Rico, Argentina, Uruguay, and Chile, is called "countries with a relatively high degree of welfare state development". The second group, composed of Costa Rica, Brazil, Panama, Venezuela and Mexico, is called "countries with a medium degree of welfare state development". The third group, Colombia, Ecuador, Peru, Dominican Republic, El Salvador, Paraguay, Bolivia and Guatemala, is called "countries with a relatively low degree welfare state development".

The original plan, at the beginning of this research, was to adopt the division of the countries into two groups, as developed by Segura-Ubiergo (2007, p. 30, Table 2.1): 
Table 3 Results of the coverage dimension index (CDI) after PCA on 3 coverage indicators from 17 countries between 1980s and 2000s

The CDI results were

standardized for

comprehensibility (1.0 represents the country with the most developed coverage dimension, and 0.0 the least developed)

Table 4 Results of the outcomes dimension index (ODI) after PCA on 3 outcomes indicators from 17 countries between 2000 and 2010

The ODI results were

standardized for

comprehensibility (1.0 represents the country with the most developed outcomes dimension, and 0.0 the least developed)

\begin{tabular}{lrl}
\hline & CDI & $\begin{array}{l}\text { CDI }(\max =1, \\
\min =0)\end{array}$ \\
\hline Puerto Rico & -2.599 & 1.000 \\
Argentina & -2.477 & 0.972 \\
Uruguay & -2.024 & 0.869 \\
Chile & -1.552 & 0.761 \\
Brazil & -0.972 & 0.629 \\
Costa Rica & -0.939 & 0.622 \\
Panamá & -0.705 & 0.569 \\
Venezuela & -0.077 & 0.425 \\
México & 0.202 & 0.362 \\
Dominican Republic & 0.961 & 0.189 \\
El Salvador & 1.229 & 0.128 \\
Perú & 1.260 & 0.121 \\
Colombia & 1.370 & 0.096 \\
Bolivia & 1.450 & 0.077 \\
Ecuador & 1.492 & 0.068 \\
Paraguay & 1.590 & 0.046 \\
Guatemala & 1.790 & 0.000 \\
\hline
\end{tabular}

\begin{tabular}{lll}
\hline & ODI & $\begin{array}{l}\text { ODI }(\max =1, \\
\min =0)\end{array}$ \\
\hline Puerto Rico & -3.059 & 1.000 \\
Argentina & -1.453 & 0.685 \\
Chile & -1.083 & 0.613 \\
Costa Rica & -0.667 & 0.531 \\
Uruguay & -0.515 & 0.501 \\
Panamá & -0.318 & 0.463 \\
Ecuador & -0.179 & 0.435 \\
Venezuela & -0.156 & 0.431 \\
México & 0.025 & 0.395 \\
Colombia & 0.053 & 0.390 \\
Perú & 0.271 & 0.347 \\
El Salvador & 0.592 & 0.284 \\
Dominican Republic & 0.595 & 0.284 \\
Brazil & 0.811 & 0.241 \\
Paraguay & 1.141 & 0.177 \\
Guatemala & 1.903 & 0.027 \\
Bolivia & 2.041 & 0.000 \\
\hline
\end{tabular}

countries with medium-high welfare development and countries with medium-low welfare development. But after analyzing and observing the standardized MWI results in the last column of Table 5, it was considered more appropriate to group the countries into three categories, instead of two: (1) countries with MWI values ranging from 1.000 to 0.666 ; (2) 
Table 5 Results of the multidimensional welfare index (MWI) after the arithmetic mean of the standardized individual welfare indexes (SSDI, CDI and ODI) from 17 countries between 1970s and 2000s

$\begin{array}{llll}\begin{array}{l}\text { SSDI }(\max =1, \\ \min =0)\end{array} & \begin{array}{l}\text { CDI }(\max =1, \\ \min =0)\end{array} & \begin{array}{l}\text { ODI }(\max =1, \\ \min =0)\end{array} & \begin{array}{l}\text { MWI }(\max =1 \\ \min =0)\end{array}\end{array}$

High welfare state development

$\begin{array}{lllll}\text { Puerto Rico } & 0.925 & 1.000 & 1.000 & 0.975 \\ \text { Argentina } & 0.867 & 0.972 & 0.685 & 0.841 \\ \text { Uruguay } & 1.000 & 0.869 & 0.501 & 0.790 \\ \text { Chile } & 0.768 & 0.761 & 0.613 & 0.714 \\ \text { Average } & 0.890 & 0.901 & 0.700 & 0.830\end{array}$

Intermediate welfare state development

$\begin{array}{lllll}\text { Costa Rica } & 0.731 & 0.622 & 0.531 & 0.628 \\ \text { Brazil } & 0.750 & 0.629 & 0.241 & 0.540 \\ \text { Panamá } & 0.301 & 0.569 & 0.463 & 0.444 \\ \text { Venezuela } & 0.229 & 0.425 & 0.431 & 0.362 \\ \text { México } & 0.314 & 0.362 & 0.395 & 0.357 \\ \text { Average } & 0.465 & 0.521 & 0.412 & 0.466\end{array}$

Low welfare state development

$\begin{array}{lllll}\text { Colombia } & 0.375 & 0.096 & 0.390 & 0.287 \\ \text { Ecuador } & 0.108 & 0.068 & 0.435 & 0.204 \\ \text { Perú } & 0.042 & 0.121 & 0.347 & 0.170 \\ \text { Dominican } & 0.025 & 0.189 & 0.284 & 0.166 \\ \text { Republic } & & & & \\ \text { El Salvador } & 0.075 & 0.128 & 0.284 & 0.162 \\ \text { Paraguay } & 0.109 & 0.046 & 0.177 & 0.111 \\ \text { Bolivia } & 0.205 & 0.077 & 0.000 & 0.094 \\ \text { Guatemala } & 0.000 & 0.000 & 0.027 & 0.009 \\ \text { Average } & 0.117 & 0.091 & 0.243 & 0.150 \\ 17 \text { countries } & 0.401 & 0.408 & 0.400 & 0.403 \\ \text { average } & & & & \end{array}$

Countries are grouped according to their MWI result. Puerto Rico, Argentina, Uruguay and Chile with MWI results between 0.66 and 1.00 are considered countries with a relative high welfare state development. Costa Rica, Brazil, Panamá, Venezuela and México countries with MWI results between 0.33 and 0.65 are considered countries with an intermediate welfare state development. Colombia, Ecuador, Perú, Dominican Republic, El Salvador, Paraguay, Bolivia and Guatemala with MWI results between 0.00 and 0.32 are considered countries with a relative low welfare state development. MWI is a composite indicator formed by 8 indicators from 3 welfare dimensions and used to rank countries in terms of their relative welfare state development

countries with MWI values ranging from 0.665 to 0.333 ; and (3) countries with MWI values between 0.332 and 0.000 .

Countries with an MWI value within the first tertile, would be considered as countries with a relatively high degree of welfare state development, those within the second tertile as countries with medium degree of welfare state development, and those within the third tertile as countries with a relatively low degree of welfare state development. 
The MWI was standardized to facilitate an understanding of the results-in comparative terms, not absolute terms-where the number 1 represents the country with the most developed welfare state in the sample, and zero the country with least developed welfare state. The understanding had to be on comparative terms, because MWI value of 1 for Puerto Rico and zero value for Guatemala do not mean that Puerto Rico has a fully developed welfare state and Guatemala a totally undeveloped one. Rather, it means that within the sample of the 17 countries, the one that is listed first has the most developed welfare state and the one listed last the least developed welfare state. This reasoning also applies to each of the three indexes (SSDI, CDI, and ODI). In the future, when other Latin American countries be added to the analysis, one may notice changes in the MWI values of most countries. This is because the standardized values depend not only on the higher and lower ranked cases, but also on the values of the remaining countries.

\subsection{Analysis of the Three Welfare Groups According to Their Sample Averages in the Multidimensional Welfare Index}

Based on MWI, how does one assess the extent by which a group of countries is more developed or less developed in comparison with any other group? This can be done by using the three welfare indexes. The welfare state development of a group of countries can be assessed by just using a one-dimensional index of welfare as reference.

The average MWI value (0.830) of the group of countries with a high welfare state development (first group) is 1.78 more than the corresponding value of the countries with a medium welfare state development (second group), 5.52 times more than the value of the countries with a low welfare state (third group), and 2.06 times more than the sample average.

The average MWI value of the second group countries (0.466) represents $56.18 \%$ of the corresponding value of the first group countries; it is 3.10 times more than the value of the third group countries and 1.16 times more than the sample average.

The average MWI value of the third group countries (0.150) represents $18.11 \%$ of the corresponding value of the first group countries; it is $32.24 \%$ of the value of the third group countries, and $37.28 \%$ of the sample average value.

\section{Limitations}

This work presents two notable limitations related to the data used. The first limitation is the unavailability of data for all cases during the period considered in the analysis. It is impossible to know the effect it may have had the inclusion of the missing data, but it is essential to consider this limitation. The collections of data by government agencies and national statistics institutes were scarce during the decades of 1970s and 1980s, which among other things limits the availability of the data.

Another limitation is the use of different sources for the countries within each indicator. This argument could be based under the assumption that the results are not as reliable as 
having all data from each cases and indicators. If it is difficult to find all the data for the study period, still more difficult is finding the data from the same source. Moreover the international databases such as ECLAC, World Bank, SEDLAS, among others were not as developed period as in the present.

\section{Conclusion}

After a thorough analysis of Segura-Ubiergo's (2007) welfare effort index as a measure of the degree of welfare development in Latin America, it was concluded that his index lays unduly high emphasis on the spending dimension of welfare. Nonetheless, his index served as an inspiration to design a new welfare index that takes into account the multidimensionality of welfare. Using PCA, a multidimensional welfare index was built with three individual welfare indexes. These indexes represent three dimensions of welfare: spending, coverage and outcomes of welfare institutions. The composite nature of this multidimensional index rendered comparative analysis of the welfare state development in 17 Latin American and Caribbean countries possible.

The results of the comparative analysis carried out on the basis of the proposed Multidimensional Welfare Index show that Puerto Rico, Argentina, Chile and Uruguay have the most developed welfare state in the Latin American region; Costa Rica, Brazil, Panamá, Venezuela and México have an intermediate degree of welfare state development, whereas Colombia, Ecuador, Dominican Republic, Perú, El Salvador, Paraguay, Bolivia and Guatemala have the least developed welfare state. It would be worthwhile to continue looking for other possible dimensions of welfare and indicators that can serve as more comprehensive and objective multidimensional welfare indexes.

The actual economic crisis is a reminder of how the market failures can affect the well being of the society and why the welfare state is a key element in assuring a dignified life for every individual. It is desirable that developing countries continue building their welfare states so that in future cyclic economic recessions/crisis/failures the population could have at least their basic social needs covered through an institutionalized welfare state.

An additional point to note here is that if countries with a high level of welfare development, such as Sweden, Finland, Denmark, and Iceland were included in this analysis, then possibly no country in Latin America can qualify to be within the group of countries of highly developed welfare state. This is because these results are relative and comparable only among Latin American and the Caribbean countries.

Acknowledgments This paper is in part possible by funding of the Spanish Ministry of Education, Culture and Sport (FPU fellowship). I would like to thank Manuel Sánchez de Dios, James L. Dietz, Mayrin García, Vladimir Alvarado, Marcia Santacruz, Camilo Vial and participants at the XXII World Congress of Political Science Panel: "Welfare Policies in Latin America and Developing Countries: Is Universalism of Social Rights Possible?" who provided much appreciated comments on earlier drafts of this article. Shortcomings, of course, remain my responsibility.

\section{Appendix}

See Table 6. 
m

产

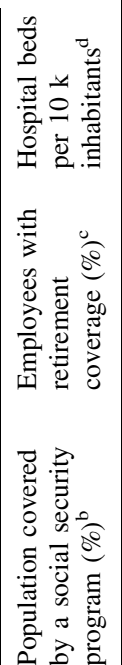

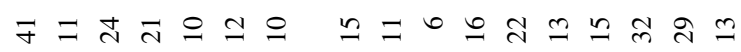

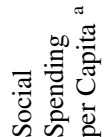

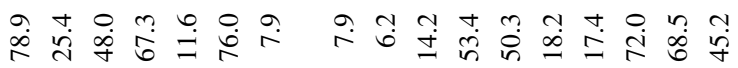

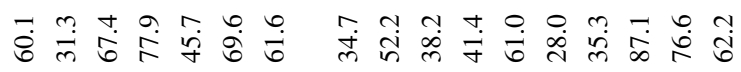

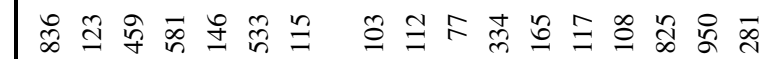

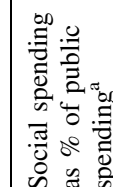




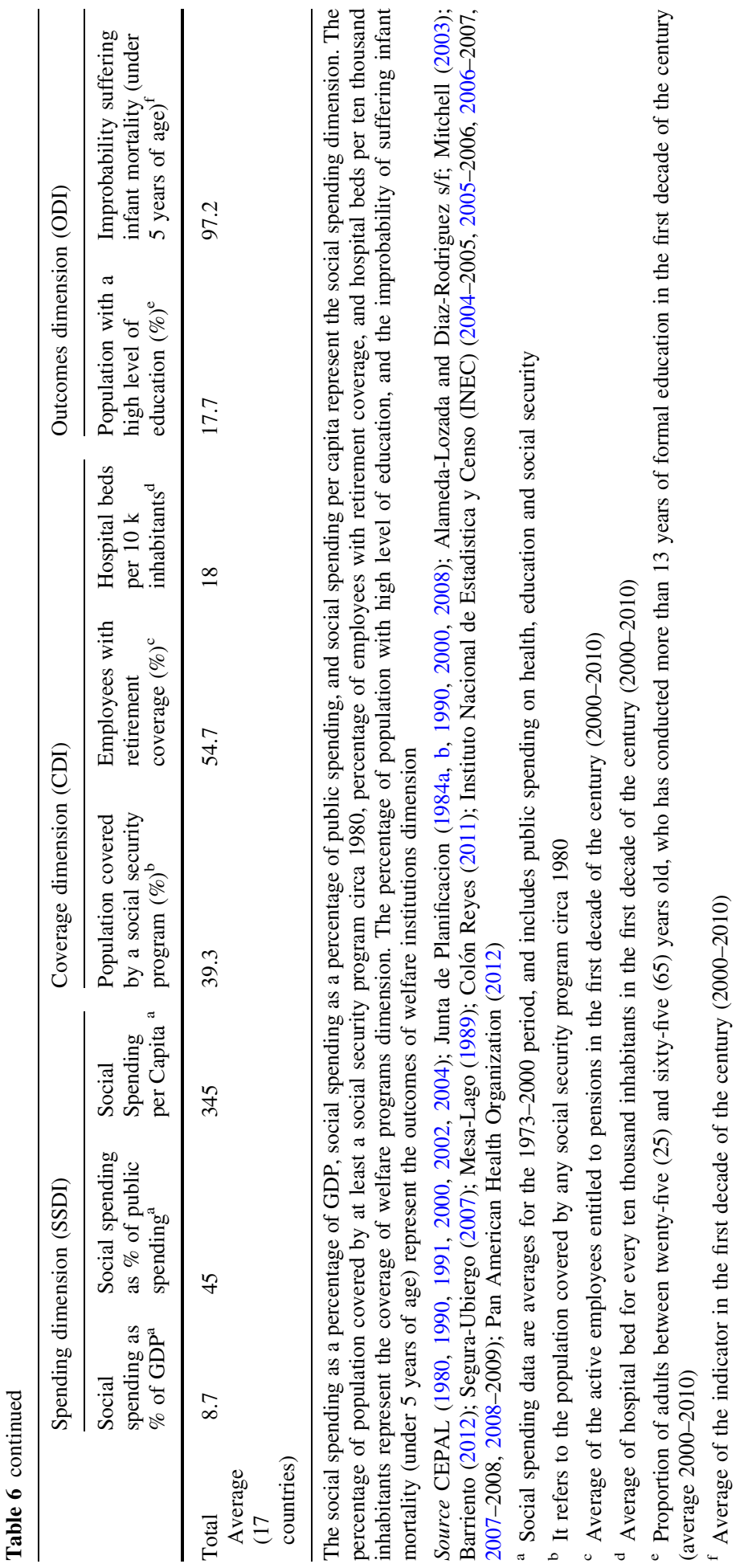




\section{References}

Abeyasekera, S. (2002). Multivariate methods for index construction. In S. Abeyasekera, \& P. Ward (Eds.), Models for predicting expenditure per adult equivalent for AMMP sentinel surveillance sites (Vol. Dar es Salaam, Adult Morbidity and Mortality Project). Tanzania: Tanzanian Ministry of Health.

Alameda-Lozada, J. I., \& Díaz-Rodríguez, I. D. C. (2009). Index of sustainable economic welfare for Puerto Rico. UPR, Recinto Universitario de Mayagüez: Instituto Tropical de Energía, Ambiente y Sociedad.

Barba, C. (2006). La reforma económica y la reforma social en América Latina: regímenes de bienestar en transición. In E. Valencia \& G. Ordoñez (Eds.), Alternancia, políticas sociales y desarrollo regional en México (pp. 51-83). Tijuana: Colef/UdeG.

Barriento, M. (2012). Index mundi. http://www.indexmundi.com.

Barrientos, A. (2011). Social protection and poverty. International Journal of Social Welfare, 20(3), 240-249. doi:10.1111/j.1468-2397.2011.00783.x.

Catell, R. B. (1965). Factor analysis: An introduction to essentials. Biometrics, 21, 190-215.

CEDLAS, \& Banco Mundial Socio-Economic Database for Latin America and the Caribbean. http://sedlac. econo.unlp.edu.ar/eng/index.php. Accessed 20/1/2012.

CEPAL. (1980). Anuario Estadístico de América Latina y el Caribe. Santiago de Chile: Naciones Unidas. CEPAL. (1990). Anuario Estadístico de América Latina y el Caribe. Santiago de Chile: Naciones Unidas. CEPAL. (1991). Anuario Estadístico de América Latina y el Caribe. Santiago de Chile: Naciones Unidas. CEPAL. (2000). Anuario Estadístico de América Latina y el Caribe. Santiago de Chile: Naciones Unidas. CEPAL. (2002). Anuario Estadístico de América Latina y el Caribe. Santiago de Chile: Naciones Unidas. CEPAL. (2004). Anuario Estadístico de América Latina y el Caribe. Santiago de Chile: Naciones Unidas.

Colón Reyes, L. I. (2011). Sobrevivencia, pobreza y "mantengo", La politica asistencialista estadounidense en Puerto Rico: el PAN y el TANF. San Juan: Ediciones Callejón.

Dunteman, G. H. (1989). Principal component analysis. Quantitative applications in the social sciences series. Thousand Oaks, CA: Sage.

Esping-Andersen, G. (1990). The three worlds of welfare capitalism. Princeton, NJ: Princeton University Press.

Esping-Andersen, G. (1996). Welfare states in transition: National adaptations in global economy. London: Sage.

Gough, I., \& Wood, G. (2004). Insecurity and welfare regimes in Asia, Africa and Latin America. Cambridge: Cambridge University Press.

Hotelling, H. (1933). Analysis of a complex statistical variables into principal components (Vol. 24). Baltimore: Warwick \& York.

Huber, E. (1996). Options for social policy in Latin America: Neoliberal vs social democratic models. In G. Esping-Andersen (Ed.), Welfare states in transition: National adaptations in global economies. London: Sage.

Huber, E., Mustillo, T., \& Stephens, J. D. (2008). Politics and social spending in Latin America. The Journal of Politics, 70(02), 420-436.

Huber, E., \& Stephens, J. D. (2012). Democracy and the left. Social policy and inequality in Latin America. Chicago: The University of Chicago Press.

Instituto Nacional de Estadística y Censo (INEC). (2004-2005). Encuesta de Mercado Laboral: Situación de la Población Ocupada. (http://www.contraloria.gob.pa/inec/).

Instituto Nacional de Estadística y Censo (INEC). (2005-2006). Encuesta de Mercado Laboral: Situación de la Población Ocupada. (http://www.contraloria.gob.pa/inec/).

Instituto Nacional de Estadística y Censo (INEC). (2006-2007). Encuesta de Mercado Laboral: Situación de la Población Ocupada. (http://www.contraloria.gob.pa/inec/).

Instituto Nacional de Estadística y Censo (INEC). (2007-2008). Encuesta de Mercado Laboral: Situación de la Población Ocupada. (http://www.contraloria.gob.pa/inec/).

Instituto Nacional de Estadística y Censo (INEC). (2008-2009). Encuesta de Mercado Laboral: Situación de la Población Ocupada. (http://www.contraloria.gob.pa/inec/).

Junta de Planificación. (1984). Ingreso y Producto. San Juan: Oficina del Gobernador.

Junta de Planificación. (1984b). Suplemento Especial: Series Históricas de las Cuentas Sociales. In Ingreso y Producto. San Juan: Oficina del Gobernador.

Junta de Planificación. (1990). Ingreso y Producto. San Juan: Oficina del Gobernador.

Junta de Planificación. (2000a). Censo Año 2000. http://www.census.gov/census2000/states/pr.html.

Junta de Planificación. (2000). Ingreso y Producto. San Juan: Oficina del Gobernador.

Junta de Planificación. (2008). Ingreso y Producto. San Juan: Oficina del Gobernador.

Martínez Franzoni, J., \& Voorend, K. (2009). Sistemas de patriarcado y regímenes de bienestar en América Latina. ¿Una cosa lleva a la otra? Documento de trabajo 37. Madrid: Fundación Carolina-CeALCI. 
Mesa-Lago, C. (1989). Ascent to bankruptcy: Financing social security in Latin America. Pittsburgh: University of Pittsburgh Press.

Mesa-Lago, C. (1994). Changing social security in Latin America. London: Lynne Rienner.

Mitchell, B. R. (2003). International historical statistics: The Americas, 1750-2000. New York: Palgrove MacMillan.

Molina, C. G. (2006). Universalismo basico: Una nueva politica social para America Latina. Washington, D.C: Editorial Planeta.

Negociado de Estadisticas del Trabajo. (2011). Serie Historica de Empleo y Desempleo, Puerto Rico. San Juan: Departamento del Trabajo y Recursos Humanos.

OECD, \& European Commission. (2008). Handbook on constructing composite indicators: Methodology and user guide. Paris: OECD.

Pan American Health Organization. (2012). Regional core health data initiative. http://www.paho.org/ English/SHA/coredata/tabulator/newTabulator.htm. World Health Organization.

Pearson, K. (1901). On lines and planes of closest fit to systems of points in space. Philosophical Magazine, 2(11), 559-572.

PNUD. (2011). Indicadores internacionales sobre desarrollo humano. http://hdrstats.undp.org/es/ indicadores/69206.html. Accessed 24/1/2012.

Pol, J. C., \& Silvestrini, R. (2004). Crimen y economía subteranea en Puerto Rico. Revista de Ciencias Sociales, 13, 106-131.

Roberts, D. (n.d.). Principal components analysis and redundancy analysis (Vol. lab7). http://ecology.msu. montana.edu/labdsv/R/labs/lab7/lab7.html. Montana State University.

Rawlings, L. B., \& Rubio, G. M. (2003). Evaluacion del impacto de los programas de transferencias condicionadas en efectivo. Cuadernos de Desarrollo Humano.

Riesco, M. (2009). Latin America: a new developmental welfare state model in the making? International Journal of Social Welfare, 18, S22-S36. doi:10.1111/j.1468-2397.2009.00643.x.

Schuschny, A., \& Soto, H. (2009). Guía metodológica: Diseño de indicadores compuestos de desarrollo sostenible. Santiago de Chile: Comision Economica para America Latina y el Caribe (CEPAL), Naciones Unidas.

Segura-Ubiergo, A. (2007). The political economy of the welfare state in Latin America: Globalization, democracy and development. New York: Cambridge University Press.

Sewall, R. G. (2008). Conditional cash transfer programs in Latin America. The SAIS Review of International Affairs, 28(2), 175-187.

Sottoli, S. (2000). La política social en América Latina bajo el signo de la economía de Mercado y la democracia. Instituto de Investigaciones Sociales. Revista Mexicana de Sociologia, 62(4, octubrediciembre), 43-65.

Uriel Jiménez, E. (1995). Análisis de Datos. Series temporales y análisis multivariante. Madrid: Editorial AC.

US Census Bureau. (n.d.). American fact finder. http://factfinder2.census.gov/faces/nav/jsf/pages/ searchresults.xhtml.

Villatoro, P. (2005). Estrategias y programas de reduccion de la pobreza en America Latina y el Caribe. Politicas economicas y sociales en la integracion. Caracas: Sistema Economico Latinoamericano, SELA.

Vyas, S., \& Kumaranayake, L. (2006). Constructing socio-economic status indices: How to use principal components analysis. Health Policy and Planning, 21, 459-468.

Wuensch, K. L. (2004). Principal component analysis. http://core.ecu.edu/psyc/wuenschk/MV/FA/PCA. doc. 